\title{
Nanostructured carbon materials decorated with organophosphorus moieties: synthesis and application
}

\author{
Giacomo Biagiotti ${ }^{1}$, Vittoria Langè ${ }^{1}$, Cristina Ligi ${ }^{1}$, Stefano Caporali ${ }^{2,3}$, \\ Maurizio Muniz-Miranda ${ }^{1}$, Anna Flis ${ }^{4}$, K. Michał Pietrusiewicz ${ }^{4}$, Giacomo Ghini ${ }^{5}$, \\ Alberto Brandi ${ }^{1}$ and Stefano Cicchi ${ }^{* 1}$
}

\author{
Full Research Paper \\ Address: \\ ${ }^{1}$ Dipartimento di Chimica Ugo Schiff Università di Firenze, Via della \\ Lastruccia 3-13, 50019 Sesto Fiorentino, Italy, ${ }^{2}$ Consorzio \\ Interuniversitario Nazionale per la Scienza e Tecnologia di Materiali \\ INSTM, 50123 Firenze, Italy, ${ }^{3}$ Istituto dei Sistemi Complessi Consiglio \\ Nazionale delle Ricerche, 50019 Sesto Fiorentino, Italy, ${ }^{4}$ Department \\ of Organic Chemistry Maria Curie-Skłodowska University, ul. Gliniana \\ 33, 20-614 Lublin, Poland and ${ }^{5}$ Nanesa S.r.I. Via Setteponti 143 - 1, \\ 52100 Arezzo, Italy \\ Email: \\ Stefano Cicchi* - stefano.cicchi@unifi.it \\ * Corresponding author

\section{Keywords:} \\ azides; click chemistry; heterogeneous catalysis; organocatalysis; \\ phosphorus \\ Beilstein J. Nanotechnol. 2017, 8, 485-493. \\ doi:10.3762/bjnano.8.52 \\ Received: 08 December 2016 \\ Accepted: 02 February 2017 \\ Published: 22 February 2017 \\ Associate Editor: J. J. Schneider \\ (c) 2017 Biagiotti et al.; licensee Beilstein-Institut. \\ License and terms: see end of document.
}

\begin{abstract}
A new synthetic approach for the production of carbon nanomaterials (CNM) decorated with organophosphorus moieties is presented. Three different triphenylphosphine oxide (TPPO) derivatives were used to decorate oxidized multiwalled carbon nanotubes (ox-MWCNTs) and graphene platelets (GPs). The TPPOs chosen bear functional groups able to react with the CNMs by Tour reaction (an amino group), nitrene cycloaddition (an azido group) or CuAAC reaction (one terminal $\mathrm{C}-\mathrm{C}$ triple bond). All the adducts were characterized by FTIR, Raman spectroscopy, TEM, XPS, elemental analysis and ICP-AES. The cycloaddition of nitrene provided the higher loading on ox-MWCNTs and GPs as well, while the Tour approach gave best results with nanotubes (CNTs). Finally, we investigated the possibility to reduce the TPPO functionalized CNMs to the corresponding phosphine derivatives and applied one of the materials produced as heterogeneous organocatalyst in a Staudinger ligation reaction.
\end{abstract}

\section{Introduction}

The term of carbon nanomaterial (CNMs) comprises many different allotropic species of carbon, fullerene, carbon nanotubes and graphene being the most studied and used. Since their discovery [1-3], they have become very attractive for re- searchers, due to their peculiar physical and chemical proprieties such as chemical and thermal stability, electronic conductivity, and their nanometric dimensions that prompted their application in chemistry of materials [4]. Furthermore, their func- 
tionalization with an increasing number of molecular moieties $[5,6]$ has extended their use in new fields ranging from biology [7] to catalysis. Despite such variability, the classes of reactions most used for their functionalization are the same and limited in number. The Tour reaction [8] is one of the most used synthetic approach for the functionalization of CNTs and GPs. In this reaction, an aniline derivative is transformed into a diazonium ion that, upon decomposition and reduction, affords a radical species, responsible for the functionalization of the graphitic surface [9]. A useful alternative to this approach is the reaction of azido derivative with CNMs: the high temperature required for the process decomposes the azido group to a reactive nitrene species that react with the graphitic surface to form an aziridine ring [10]. Finally, the use of the CuAAC reaction [11], between an azide group and a terminal alkyne, has revealed a practical synthetic approach for the decoration of CNMs with a variety of molecular moieties $[12,13]$. In this work, we present our results in the functionalization of oxidized MWCNTs 4 and multilayer graphene platelets (GPs) 5 [14] using amino- or azido-functionalized triphenylphosphine oxides $\mathbf{1}$ and $\mathbf{2}$ and the terminal alkyne $\mathbf{3}$ (see Figure 1).

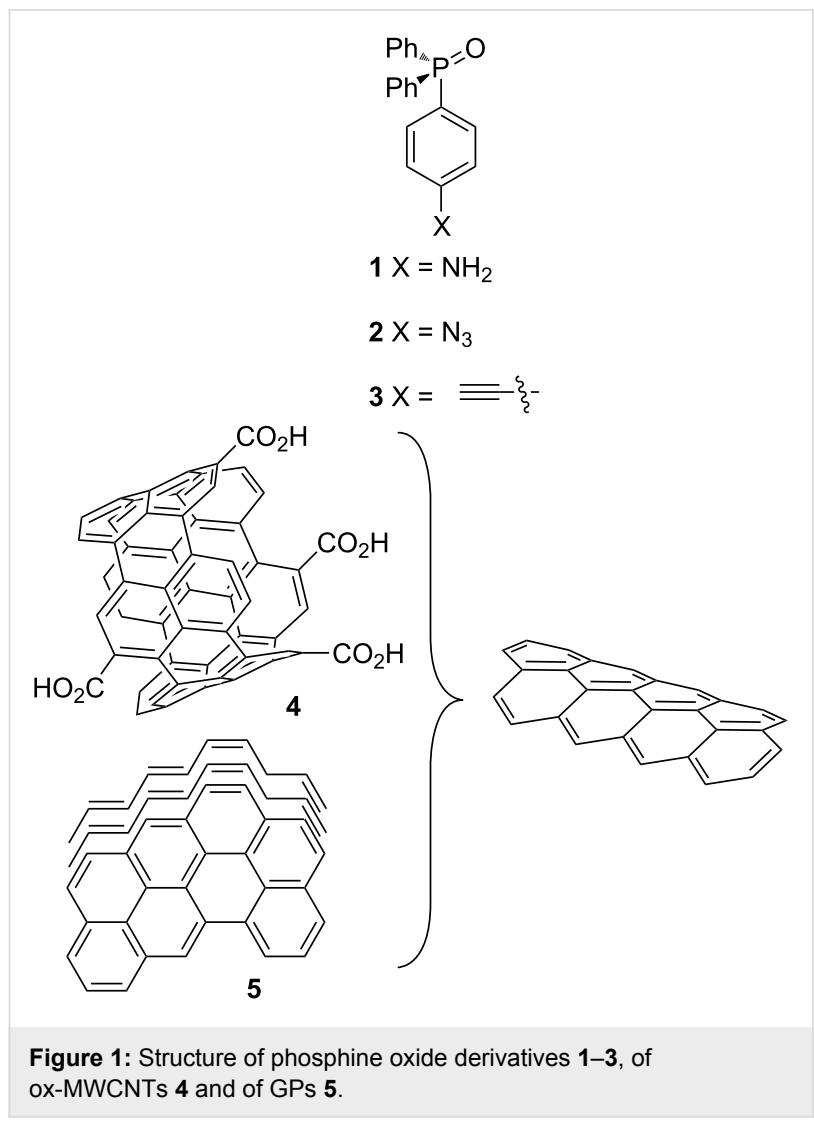

Such work led to the production of phosphine oxide substituted CNMs. A limited number of works describe the introduction of phosphorous moieties onto CNMs. Muleja et al. synthesized a
MWCNTs-TPP system modifying the nanotube with the introduction of a phenyl bromide group via diazonium coupling and then of the phosphinating reagent [15]. Hamilton et al. described the functionalization of carbon nanotube with triphenylphosphine oxide (TPPO) using the carboxylic group, introduced with the oxidation, to covalently link the TPPO [16]. Only one example describes the functionalization of a graphene based material with a phosphine, the authors report the synthesis, characterization and test of palladium nanoparticles supported on phosphine decorated graphene oxide [17]. The interest in the introduction of a phosphine oxide group in CNMs is due to its ability to promote a wide varieties of chemical transformation [18]. Phosphines have found large application in organocatalytic processes $[19,20]$ and, recently, also triphenylphosphine oxide (TPPO) have found similar application [2124]. Despite their utility, very few examples of heterogeneous catalysts are described. One example was reported by Tang, who developed a phosphine oxide derivative linked to a polystyrene resin [25]. For this reason, a new class of phosphine oxide functionalized CNMs can be of interest. Not to say of the wide possibilities offered by the production of metal nanohybrid upon complexation of metal nanoparticles or metal ions by the phosphine functionalities [26].

\section{Results and Discussion}

The CNMs substrates used for this study are oxidized MWCNTs 4 and GPs 5. The oxidation of pristine MWCNTs [27,28] afforded an easily dispersible material and removed any possible metal impurities present in the starting substrate. GPs were used as example of easily accessible and low cost graphitic material (see Experimental section). The first functionalization studied was the reaction of (4-aminophenyl)diphenylphosphine oxide (1) with the two substrates $\mathbf{4}$ and $\mathbf{5}$ (Scheme 1).

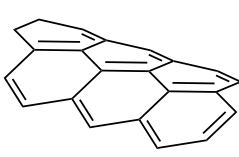

4 ox-MWCNTs 5 GPs

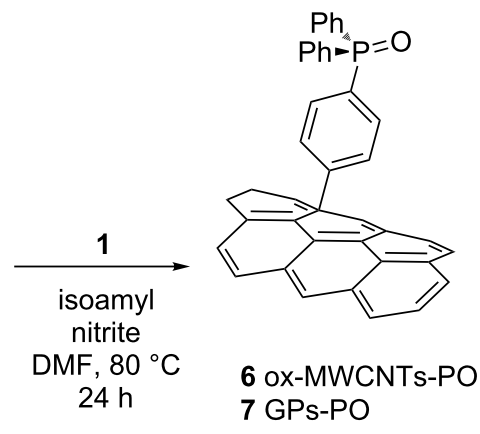

7 GPs-PO
Scheme 1: The Tour reaction applied on CNMs 4 and 5.

This reaction was carried out using the well described Tour protocol [29,30]: the nanomaterials and $\mathbf{1}$ were dispersed in $\mathrm{DMF}$, then isopentyl nitrite was added and the mixture kept at 
$80^{\circ} \mathrm{C}$ for $24 \mathrm{~h}$. The ox-MWCNTs derivative 6 was isolated through filtration over a $0.2 \mu \mathrm{m}$ PTFE membranes followed by repeated washings with different solvents to remove excess reagents, while the GPs 7 was recovered after several cycles of centrifugation and dispersion.

Subsequently, substrates $\mathbf{4}$ and $\mathbf{5}$ were reacted with the azido derivative 2 (Scheme 2).

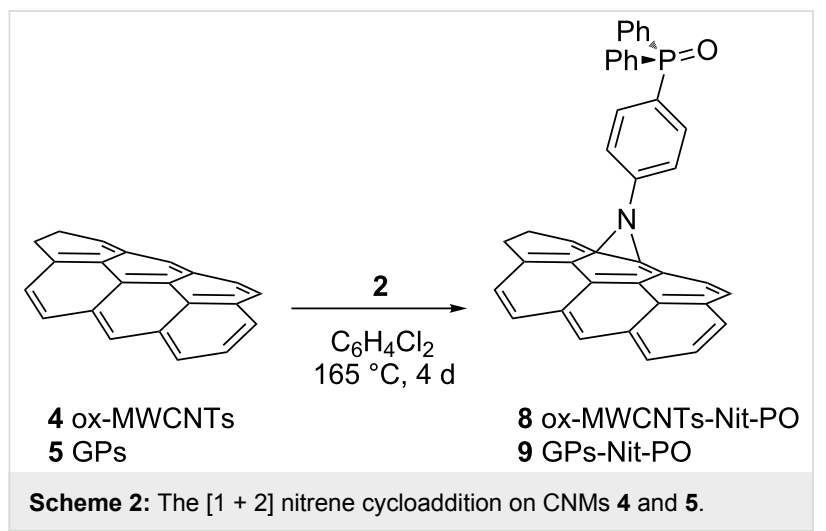

The mixture of the reagents in dichlorobenzene was kept in the ultrasound bath for $25 \mathrm{~min}$, to obtain a homogeneous dispersion, and subsequently stirred at $165{ }^{\circ} \mathrm{C}$ for four days [10,31,32]. Again CNTs derivative 8 was more easily isolated by filtration and repeated washing for complete removal of the excess reagents while GPs-Nit-PO derivative 9 was recovered using cycles of centrifugation and re-dispersion of the carbon material in a 1:1 isopropyl ether-isopropanol solution.

The decoration of the carbonaceous substrates, $\mathbf{4}$ and $\mathbf{5}$, with (4-ethynylphenyl)diphenylphosphine oxide (3), via the CuAAC reaction, required their previous modification with the introduction of azido groups. For this purpose, CNMs 4 and $\mathbf{5}$ were reacted with 4-azidoaniline (10) following, again, the Tour protocol affording compounds 11 and 12 (Scheme 3) [33].

The successful decoration of NMs $\mathbf{1 1}$ and $\mathbf{1 2}$ was confirmed by elemental analysis and IR spectroscopy (see Supporting Information File 1, Figures S9 and S10) and, finally, they were reacted with compound 3 to afford the functionalized compounds 13 and 14 (Scheme 3).

The characterization of each material produced was performed via elemental analysis, inductively coupled ion plasma atomic emission spectroscopy (ICP-AES) analysis, IR and Raman spectroscopy, XPS analysis. Elemental and ICP analyses were useful for the determination of the loading after each chemical transformation. For example, the \% content of nitrogen in compounds $8(1.32 \%)$ and $9(0.42 \%)$ suggested a loading degree for

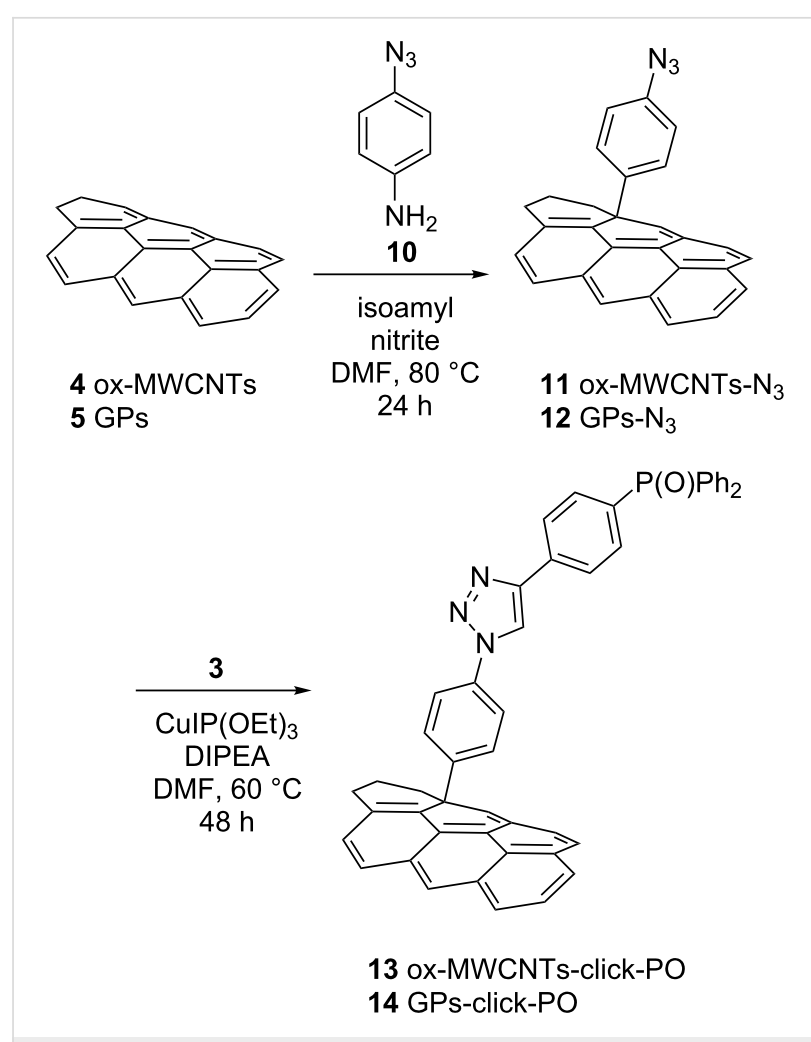

Scheme 3: The Tour reaction with 4-azido aniline (10) on CNMs 4 and 5 and the subsequent CuAAC reaction.

$8(0.58 \mathrm{mmol} / \mathrm{g})$ and $9(0.3 \mathrm{mmol} / \mathrm{g})$. The values obtained for 11 and 12 indicated a functionalization degree of $1.63 \mathrm{mmol} / \mathrm{g}$ and $0.075 \mathrm{mmol} / \mathrm{g}$, respectively. The presence of the azido group in 11 and 12 was confirmed by the signal at $2118 \mathrm{~cm}^{-1}$ in the FTIR spectra (see Supporting Information File 1, Figures S9 and S10). The ICP-AES was used to determine the amount of phosphorus in the complex matrix. The samples were previously mineralized by treatment with nitric acid and a hydrogen peroxide solution at high temperature in microwave. The data obtained are reported in Table 1.

\begin{tabular}{|llll|}
\hline \multicolumn{4}{|l|}{ Table 1: ICP-Analysis results and P loading. } \\
\hline Entry & Compound & ICP-AES P \% & mmol/g P \\
\hline 1 & 4 & - & - \\
2 & 5 & - & - \\
3 & $\mathbf{6}$ & 1.26 & 0.40 \\
4 & $\mathbf{7}$ & 0.27 & 0.09 \\
5 & $\mathbf{8}$ & 1.81 & 0.58 \\
6 & $\mathbf{9}$ & 0.61 & 0.20 \\
7 & $\mathbf{1 3}$ & 0.85 & 0.27 \\
8 & $\mathbf{1 4}$ & 0.06 & 0.02 \\
\hline
\end{tabular}

From the data reported in Table 1 it is evident the higher reactivity of ox-MWCNTs 4 (entries 3, 5 and 7) respect to GPs 5 
(entries 4,6 and 8) as it was expected considering the different nature of the two substrates [34]. For both series of reactions the higher efficiency was found for the nitrene cycloaddition (Table 1 , entries 5 and 6 ) followed by the Tour reaction (Table 1 , entries 3 and 4). The decoration using the CuAAC reaction (Table 1, entries 7 and 8 ) revealed the less efficient. To be noted that this is not due to a poor content in the azido component (see data for compounds $\mathbf{1 1}$ and 12) but to the low reactivity found in the CuAAC step. To be noted is the good agreement for the loading values obtained with the elemental analysis (see earlier) and with the ICP AES analysis for compound 8 and 9 (Table 1, entries 5 and 6).

$\mathrm{X}$-ray photoelectron spectroscopy analysis showed the presence of the $\mathrm{P}(\mathrm{V})$ atoms in all the samples considered. The samples for the analysis where prepared by dispersion of $1 \mathrm{mg}$ of substance in $1 \mathrm{~mL}$ of isopropanol and the dispersion was drop casted on a cleaned glass support. The spectra of all TPPO decorated materials were recorded and all showed a signal at a binding energy of $132.8 \mathrm{eV}$, where the two component $2 \mathrm{p}^{3 / 2}$ and $2 \mathrm{p}^{1 / 2}$, compatible with a phosphine oxide species, can be observed (see Figure 2).

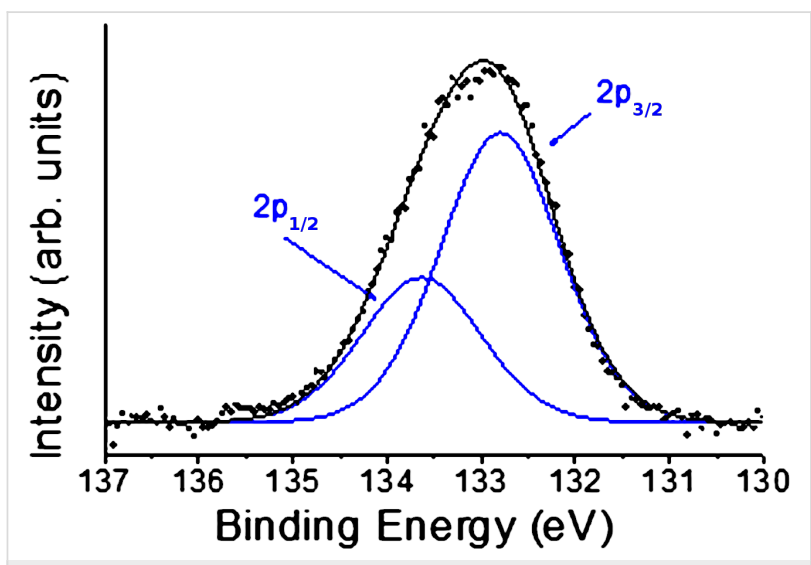

Figure 2: Fitting of the XPS spectrum characteristic of $P$ collected on GPs-Nit-PO 9 showing the two components $\left(2 p_{1 / 2}\right.$ and $\left.2 p_{3 / 2}\right)$ relative to the phosphine oxide group (for XPS spectra of the other compounds see Supporting Information File 1).

Raman spectroscopy analyses were performed on the most functionalized samples, compound $\mathbf{8}$ and 9 (see Figure 3). Generally, CNMs show two main bands in their Raman spectra: one at $\approx 1580 \mathrm{~cm}^{-1}$ (G band) related to $\mathrm{sp}^{2}$ graphitic domain and the second at $\approx 1360 \mathrm{~cm}^{-1}$ (D band) attributed to the amorphous carbon or deformation vibrations of a hexagonal ring [15]. Raman spectra of ox-MWCNTs 4 (Figure 3, bottom) showed the D and $\mathrm{G}$ bands centered at 1320 and $1607 \mathrm{~cm}^{-1}$, respectively [35], while for compound $\mathbf{8}$ the band were centered at 1312 and $1590 \mathrm{~cm}^{-1}$. Despite the ox-MWCNTs 4 already showed an intense $\mathrm{D}$ band $\left(I_{\mathrm{D}} / I_{\mathrm{G}}=2.57\right)$, the functionalization further in-

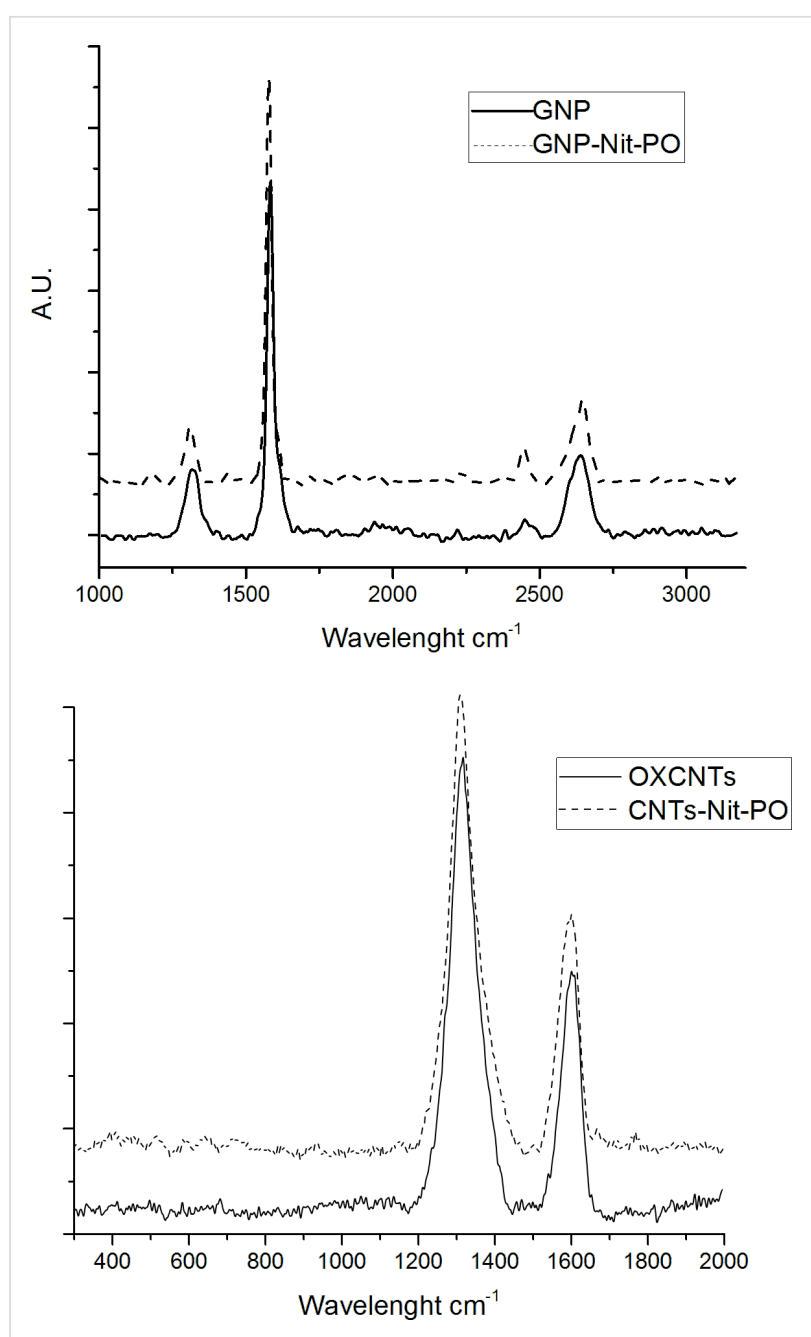

Figure 3: Raman spectra: GPs 5 vs GPs-Nit-PO 9 (top), ox-MWCNTs 4 vs ox-MWCNTs-Nit-PO 8 (bottom).

creased the D band intensity, so that the $I_{\mathrm{D}} / I_{\mathrm{G}}$ for compound $\mathbf{8}$ raised to 3.58. The Raman characterization of the GPs 5 (Figure 2, top) showed the D and G bands at 1320 and $1580 \mathrm{~cm}^{-1}$ with a visible shoulder at $1610 \mathrm{~cm}^{-1}$, while at $2640 \mathrm{~cm}^{-1}$ is visible the overtone band 2D typical of graphene. This latter band, sharp and intense in monolayer graphene, is broadened confirming the high number of layers of the GPs. Upon functionalization The GPs-Nit-PO 9 spectrum showed the same bands with no significant differences respect to $\mathbf{5}$.

TEM images of functionalized CNM are shown in Figure 4. No significant difference can be found in the morphology of the materials. In particular, as confirmed by the Raman analysis, the GPs present a multilayer structure and no further exfoliation of the multi-layer GPs was observed.

A useful extension of these synthetic approaches is the chance to reduce the $\mathrm{P}=\mathrm{O}$ moiety to the corresponding phosphine. The 


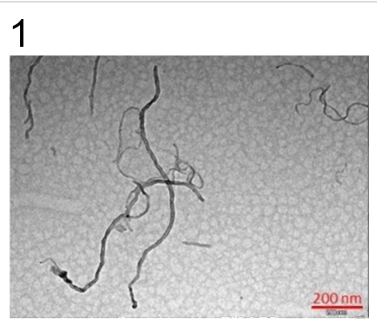

2

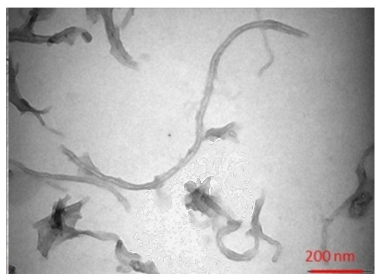

3

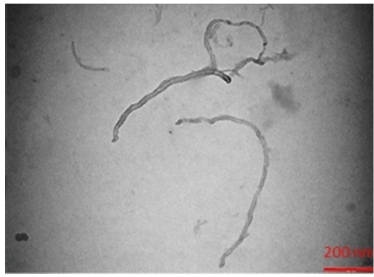

4

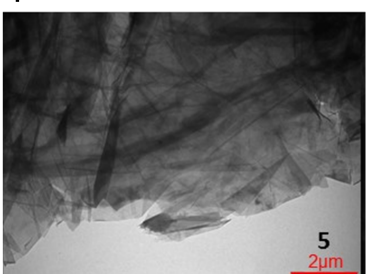

5

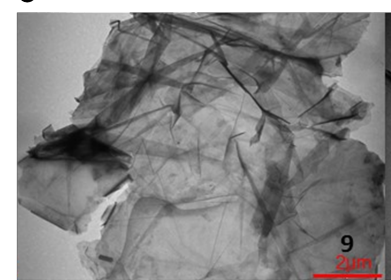

6

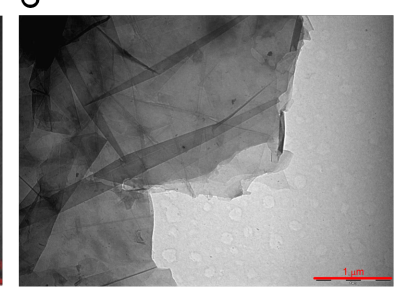

Figure 4: TEM images of ox-MWCNTs 4 (1), ox-MWCNTs-PO 6 (2), ox-MWCNTs-Nit-PO 8 (3), GPs 5 (4) GPs-PO 7 (5), GPs-Nit-PO 9 (6).

phosphorus-phosphorus, trichlorosilane mediated oxygen transfer protocol, developed by Hamilton [16] and $\mathrm{Wu}$ [36], was used with compound 6 (Scheme 4). The reaction was carried out in a Pyrex tube, heating for $48 \mathrm{~h}$, a degassed solvent solution of compound $\mathbf{6}$, trichlorosilane and triethyl phosphite as final oxygen acceptor. The reduction of the phosphine oxide moiety was followed by XPS analysis and confirmed by FTIR spectroscopy.

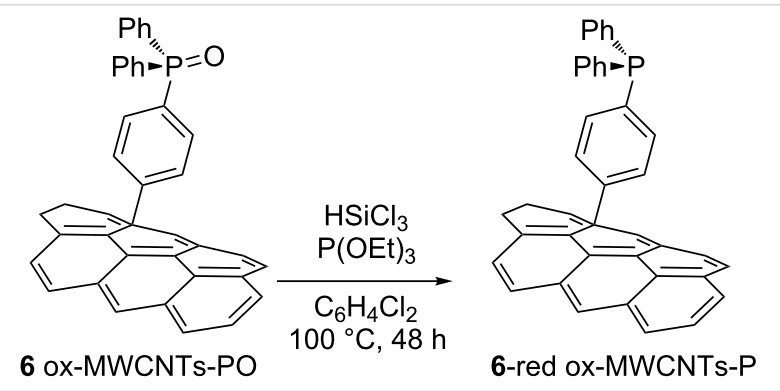

Scheme 4: Reduction of phosphine oxide 6 to the corresponding phosphine 6-red.

Figure 5 shows the XPS spectra registered on starting material 6 $(t=0)$, and of the reaction product after $24 \mathrm{~h}$ and after $48 \mathrm{~h}$. The XPS analysis of the starting material showed only the peak at binding energy $132.8 \mathrm{eV}$ (related to presence the phosphine oxide group), after $24 \mathrm{~h}$ a new peak, related to the reduced

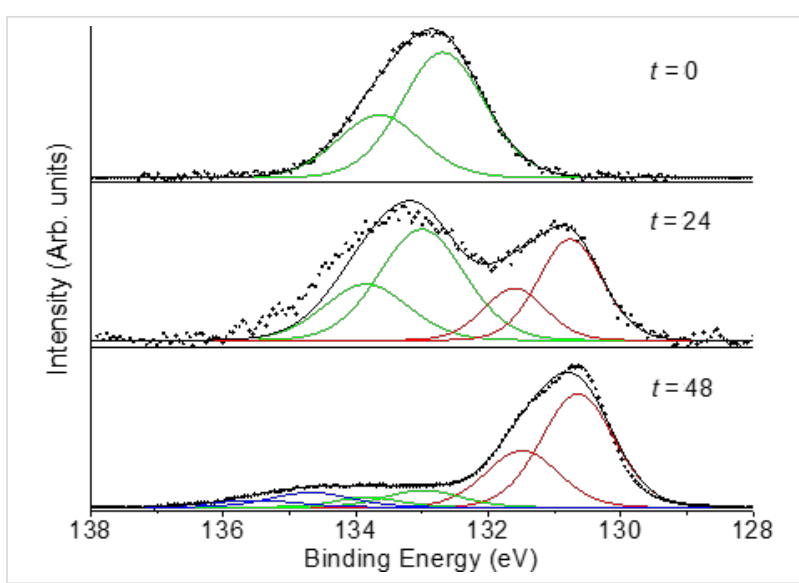

Figure 5: XPS analysis of samples form the reduction reaction of compound 6: starting material (top), after $24 \mathrm{~h}$ (middle), after $48 \mathrm{~h}$ (bottom).

phosphorus atoms, appeared at $130.8 \mathrm{eV}$, accordingly with value reported by Swartz et al. [37]. After $48 \mathrm{~h}$ the peak at $130.8 \mathrm{eV}$ is the main one showing that the reaction is almost complete.

The FTIR spectroscopy confirmed the reduction of the phosphine oxide group with the disappearance of the band at $1114 \mathrm{~cm}^{-1}$ related to the $\mathrm{P}=\mathrm{O}$ stretching vibration (Supporting Information File 1, Figures S2-S4).

The most functionalized material, compound $\mathbf{8}$, was finally tested as organocatalyst in a Staudinger ligation of carboxylic acids and azides being inspired by work of Ashfeld and co-workers [24]. In this work the reaction between a carboxylic acid and an organic azide, to afford the corresponding amide is catalyzed by $\mathrm{PPh}_{3}(10 \mathrm{~mol} \%)$. The process is general and affords high yields. The catalytic cycle is guaranteed by the presence of $\mathrm{PhSiH}_{3}$ that reduces the triphenylphosphine oxide formed to the starting phosphine. In our experiments we substituted triphenylphosphine with the reduced form of compound $\mathbf{8}$, 8-red (see Scheme 5).

As a matter of fact, the reactions reported in Scheme 5 were successful and afforded the expected amides 17 and 19 and 21 in acceptable yields. For a correct comparison with the higher yields reported for the reaction performed in homogeneous phase (94\%, 95\% and $80 \%$, respectively) it should be stressed that in these experiments the amount of phosphine used is one order of magnitude lower (1\% calculated on the basis of the $\mathrm{P}$ loading in compound 8). Further experiments aimed to evaluate the action of the catalyst in new reaction cycles revealed a fast degradation of the efficiency: the yield of amide $\mathbf{1 7}$ dropped to $30 \%$ and $20 \%$ in the second and third cycles while no conversion was observed in the second cycle for amide 19. The yield of compound 21 was $48 \%$ in the second cycle. 


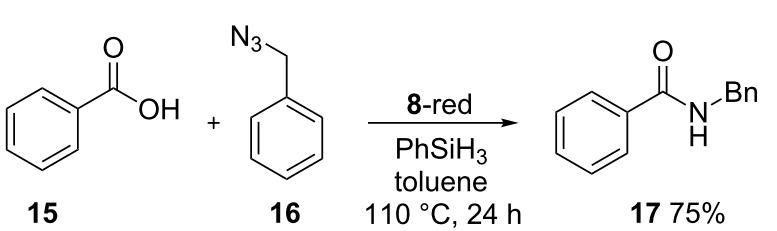

15 $110{ }^{\circ} \mathrm{C}, 24 \mathrm{~h}$

$1775 \%$<smiles>O=C(O)/C=C/c1ccccc1</smiles>

$+16$

18<smiles>COc1ccc([N+]#N)cc1</smiles>

20 $110^{\circ} \mathrm{C}, 24 \mathrm{~h}$<smiles>O=C(/C=C/c1ccccc1)NCc1ccccc1</smiles>

$1955 \%$<smiles>COc1ccc(NC(=O)/C=C/c2ccccc2)cc1</smiles>

Scheme 5: The Staudinger ligation reaction performed with benzoic acid (15) or cinnamic acid (18), and benzyl azide (16) or 4-azidoanisole (20) and compound 8-red as catalyst.

\section{Conclusion}

In conclusion, we developed a simple procedure for the covalent decoration of oxidized multi-walled carbon nanotubes and graphene-based materials with three different TPPO derivatives. Materials were completely characterized by FTIR, Raman, XPS spectroscopy and TEM, the loading of phosphorus were quantified by ICP-AES. The higher loading was obtained with the nitrene cycloaddition on CNTs but good results were also obtained with graphene. The reduction of adduct to the correspondent TPP was also investigate, the reduction was confirmed by XPS, whose spectra showed the complete disappear of the phosphine oxide peak and the presence of the intense phosphine peak in $48 \mathrm{~h}$. The possibility to use the TPP group for further modification as binding of $\mathrm{Pd}$ nanoparticles, oxidation to phosphine sulfide and selenide are actually under investigation in our laboratory. More significantly, we have explored the ability of one of these materials (the one with the highest loading in phosphine oxide moiety, compound 8) as heterogeneous catalyst in a Staudinger ligation reaction. Despite the process is still to be optimized, concerning the yield and the recycling of the catalyst, the very low amount of phosphine oxide employed make this approach promising for the development of efficient nanostructured materials useful in organocatalysis.

\section{Experimental Materials}

MWCNTs were purchased from Sigma-Aldrich reagent, O.D. $\times$ L. $=6-9 \mathrm{~nm} \times 5 \mu \mathrm{m}$, carbon $>95 \%$, CoMoCat ${ }^{\odot}$. GPs were supplied from Nanesa in dry powder or water paste, $\mathrm{C} / \mathrm{O}$ ratio $44: 1$, carbon $>97 \%$, average flake thickness $10 \mathrm{~nm}$ (30 layers), average lateral size $10-50 \mu \mathrm{m}$. All the other reagents, whose synthesis is not described, were commercially available and have been used without any further purification, if not specified otherwise. Rf values are referred to TLC on silica gel plate $\left(0.25 \mathrm{~mm}\right.$, Merck silica gel $\left.60 \mathrm{~F}_{254}\right)$. NMR spectra were recorded on Varian Gemini $200 \mathrm{MHz}$ or Varian Mercury $400 \mathrm{MHz}$ at room temperature. Chemical shifts were reported in parts per million ( $\mathrm{ppm}$ ) relative to the residual solvent peak rounded to the nearest 0.01 for proton and 0.1 for carbon (reference: $\mathrm{CHCl}_{3}\left[{ }^{1} \mathrm{H}: 7.26,{ }^{13} \mathrm{C}: 77.2\right]$, DMSO $\left[{ }^{1} \mathrm{H}: 2.5,{ }^{13} \mathrm{C}: 39.5\right]$, $\mathrm{MeOH}\left[{ }^{1} \mathrm{H}: 3.35,{ }^{13} \mathrm{C}: 49.3\right]$. Coupling constants $J$ were reported in $\mathrm{Hz}$ to the nearest $0.01 \mathrm{~Hz}$. Peak multiplicity was indicated by $\mathrm{s}$ (singlet), d (doublet), $\mathrm{t}$ (triplet), q (quartet), $\mathrm{m}$ (multiplet) and br (broad signal). IR spectra were recorded on a Perkin-Elmer FT-IR 881 or Shimadzu FT-IR 8400s spectrometer. IR data are reported as frequencies in wavenumbers $\left(\mathrm{cm}^{-1}\right)$. UV-vis spectra were recorded on Varian Cary 4000 UV-vis spectrophotometer using $1 \mathrm{~cm}$ cell. Fluorescence spectra were registered on a Jasco FP750 spectrofluorimeter using $1 \mathrm{~cm}$ cell. Raman spectra were measured by a Renishaw RM2000 instrument with a diode laser emitting at $785 \mathrm{~nm}$. Elemental analyses were performed with a Thermofinnigan CHN-S Flash E1112 analyzer. ICP analysis were made using an Optima 2000 Perkin Elmer Inductively Coupled Plasma (ICP) Dual Vision instrument after acidic mineralization. TEM images were acquired at the electronic microscopic center CNR Florence (CE.M.E.) with a Philips CM12 with CRYO-GATAN UHRST 3500 technology, digital camera and EDAX microanalysis.

\section{Synthesis of (4-aminophenyl)diphenylphosphine oxide 1 and (4-ethynylphenyl)diphenylphosphine oxide 3}

Compounds 1 [38] and 3 [39] were synthesized by literature procedures in $64 \%$ and $72 \%$ yield, respectively. 


\section{Synthesis of (4-azidophenyl)diphenylphosphine oxide 2}

A solution of (4-aminophenyl)diphenylphosphine oxide (1, $1.06 \mathrm{~g}, 3.61 \mathrm{mmol})$ in acetone $(10 \mathrm{~mL}), \mathrm{H}_{2} \mathrm{SO}_{4}(2.7 \mathrm{~mL})$ and $\mathrm{H}_{2} \mathrm{O}(14.4 \mathrm{~mL})$ was added with a solution of $\mathrm{NaNO}_{2}(0.368 \mathrm{~g}$, $5.33 \mathrm{mmol})$ in $\mathrm{H}_{2} \mathrm{O}(2.2 \mathrm{~mL})$ at $0{ }^{\circ} \mathrm{C}$. After stirring for $1.5 \mathrm{~h}$ at $0{ }^{\circ} \mathrm{C}$, a solution of $\mathrm{NaN}_{3}(0.4 \mathrm{~g}, 6.13 \mathrm{mmol})$ in $\mathrm{H}_{2} \mathrm{O}(2 \mathrm{~mL})$ was added dropwise at $0{ }^{\circ} \mathrm{C}$. The resulting suspension was stirred for $1.5 \mathrm{~h}$ at $0{ }^{\circ} \mathrm{C}$ and at room temperature for $15 \mathrm{~h}$. After the completion of reaction, the mixture was extracted with EtOAc $(100 \mathrm{~mL})$. The combined organic extracts were washed with brine, dried over anhyd. $\mathrm{MgSO}_{4}$, filtered, and evaporated in vacuo to afford azide 2 as an off-white solid (1.09 g, 96\%). Mp $119-121{ }^{\circ} \mathrm{C} ;{ }^{1} \mathrm{H}$ NMR $(500 \mathrm{MHz}$, chloroform- $d$ ) $\delta$ 7.76-7.61 (m, 6H), 7.60-7.53 (m, 2H), 7.52-7.44 (m, 4H), 7.17-7.05 (m, $2 \mathrm{H}) ;{ }^{13} \mathrm{C}$ NMR (126 MHz, chloroform-d) $\delta 143.98(\mathrm{~d}$, $J=3.0 \mathrm{~Hz}), 133.85$ (d, $J=10.8 \mathrm{~Hz}), 132.29$ (d, $J=105.0 \mathrm{~Hz})$, $132.08(\mathrm{~d}, J=3.2 \mathrm{~Hz}), 132.01(\mathrm{~d}, J=10.1 \mathrm{~Hz}), 128.80$ (d, $J=106.9 \mathrm{~Hz}), 128.58(\mathrm{~d}, J=12.1 \mathrm{~Hz}), 119.10$ (d, $J=13.0 \mathrm{~Hz})$; ${ }^{31} \mathrm{P}$ NMR (202 MHz, chloroform- $d$ ) $\delta$ 28.61. Anal.: calcd for $\mathrm{C}_{18} \mathrm{H}_{14} \mathrm{~N}_{3} \mathrm{OP}$ : C, 67.71; H, 4.42; N, 13.16\%; found: C, 67.66; $\mathrm{H}, 4.48 ; \mathrm{N}, 13.22 \%$.

\section{Synthesis of $p$-azidoaniline 10}

Compound 10 was synthesized from 4-bromoaniline in quantitative yield following a procedure reported in literature [40].

\section{Oxidation of CNTs}

To a $100 \mathrm{~mL}$ flask were added CNTs $500 \mathrm{mg}$ and $40 \mathrm{~mL}$ of a $3: 1$ solution of $96 \%$ sulfuric acid $/ 65 \%$ nitric acid. The mixture was stirred at reflux for $30 \mathrm{~min}$, diluted with fresh water in ice bath and the acidic solution removed by centrifugation (10 $\mathrm{min}$ at $1400 \mathrm{rcf}$ ). The solid was dispersed with water and centrifuged $30 \mathrm{~min}$ at $1400 \mathrm{rcf}$. The solid was again dispersed with water, filtered over a $0.2 \mu \mathrm{M}$ PC membrane and washed until the filtered solution exhibited a neutral $\mathrm{pH}$. Purified ox-MWCNTs were collected. Yield 39\% (194.6 mg); FTIR: 3431, 1704, 1224 $\mathrm{cm}^{-1}$; Elemental analysis C, 77.72; H, 0.84; N, 0.19\%.

\section{Synthesis of CNTs-Tour-PO (6)}

To a $5 \mathrm{~mL}$ flask were added CNTs $(10 \mathrm{mg}, 0.83 \mathrm{mmol})$ and (4-aminophenyl)diphenylphosphine oxide $(1,54.3 \mathrm{mg}$, $0.185 \mathrm{mmol}$ and $2.5 \mathrm{~mL}$ of anhydrous DMF. The mixture was kept in an ultrasound bath for $10 \mathrm{~min}$, under inert atmosphere, and $19.3 \mathrm{mg}(0.165 \mathrm{mmol})$ of isopentyl nitrite were added. The mixture was stirred at $80{ }^{\circ} \mathrm{C}$ under nitrogen for $16 \mathrm{~h}$. The dispersion was diluted a 1:1 solution of isopropanol/diisopropyl ether and centrifuged for $15 \mathrm{~min}$ at $1400 \mathrm{rcf}$. The supernatant solution was removed and the solid was washed by 5 cycles of dispersion in fresh solvent and centrifugation (4 times with a 2:1 isopropanol/diisopropyl ether solution and once with a $1: 1$ solution of the same solvents. The product was finally recovered and dried to afford $15 \mathrm{mg}$ of a black powder. ICP-AES analysis: phosphorus $1.255 \%, 0.41 \mathrm{mmol} / \mathrm{g}$. FTIR (KBr): 3328 , $1724,1579,1384,1154$ and $1116 \mathrm{~cm}^{-1}$.

\section{Synthesis of GPs-Tour-PO (7)}

To a $5 \mathrm{~mL}$ flask were added GPs $11.6 \mathrm{mg}(0.95 \mathrm{mmol})$, (4-aminophenyl)diphenylphosphine oxide (1, $54.3 \mathrm{mg}$, $0.185 \mathrm{mmol}$ ) and $2.5 \mathrm{~mL}$ of anhydrous DMF. The mixture was kept in an ultrasound bath for $30 \mathrm{~min}$, under inert atmosphere, then $19.3 \mathrm{mg}(0.165 \mathrm{mmol})$ of isopentyl nitrite were added. The mixture was stirred at $80{ }^{\circ} \mathrm{C}$ under nitrogen for $16 \mathrm{~h}$. The dispersion was diluted with isopropanol and centrifuged for $15 \mathrm{~min}$ at $1400 \mathrm{rcf}$. The supernatant was removed. The solid was washed by cycle of dispersion in fresh methanol and centrifugation (six times). The product was recovered and dried (12.5 $\mathrm{mg}$ ). ICP-AES analysis: phosphorus $0.275 \%, 0.087 \mathrm{mmol} / \mathrm{g}$.

\section{Synthesis of ox-MWCNTs-nitrene-PO (8)}

To a $50 \mathrm{~mL}$ flask were added CNTs $(10 \mathrm{mg})$ and $20 \mathrm{~mL}$ of 1,2dichlorobenzene. The mixture was kept in an ultrasound bath for $30 \mathrm{~min}$. (4-Azidophenyl)diphenylphosphine oxide 2 (39 $\mathrm{mg}$ $0.12 \mathrm{mmol}$ ) was added and the dispersion sonicated again for $10 \mathrm{~min}$. The resulting dispersion was kept at $165{ }^{\circ} \mathrm{C}$ under vigorous stirring for 4 days. The mixture was filtered through a $0.2 \mu \mathrm{m}$ pore PTFE membrane and thoroughly washed with a solution of diisopropyl ether and isopropanol 1:1. The product was recovered and dried to afford $13.3 \mathrm{mg}$ of a black powder. Elemental analysis C, 76.07; H, 1.12; N, 0.82\%. ICP-AES phosphorus $1.807 \%, 0.583 \mathrm{mmol} / \mathrm{g}$. FTIR (KBr): 3312, 1718, 1559, 1164 and $1114 \mathrm{~cm}^{-1} \mathrm{P}=\mathrm{O}$ stretching.

\section{Synthesis of GPs-nitrene-PO (9)}

To a $50 \mathrm{~mL}$ flask were added GPs $(11.5 \mathrm{mg})$ and $20 \mathrm{~mL}$ of 1,2dichlorobenzene. The mixture was kept in an ultrasound bath for $30 \mathrm{~min}$. (4-Azidophenyl)diphenylphosphine oxide 2 (39 mg, $0.12 \mathrm{mmol}$ ) was added and the mixture sonicated again for $10 \mathrm{~min}$. The dispersion was kept at $165^{\circ} \mathrm{C}$ under vigorous stirring for 4 days. The mixture was then diluted with isopropanol and centrifuged $15 \mathrm{~min}$ at $1400 \mathrm{rcf}$. The supernatant was removed and the precipitate was washed by 5 cycles of dispersion and centrifugation ( $5 \mathrm{~min}$ in ultrasound bath and centrifugation for $15 \mathrm{~min}$ at $1400 \mathrm{rcf}$ ), with a solution of diisopropyl ether and isopropanol 1:1. The product was recovered and dried to afford $13.1 \mathrm{mg}$. Elemental analysis C, 90.36\%; H, 0.58; N, $0.42 \%$. ICP-AES $0.61 \%$ of phosphorous. FTIR (KBr): 1195 and $1181 \mathrm{~cm}^{-1} \mathrm{P}=\mathrm{O}$ stretching.

\section{Synthesis ox-MWCNTs- $\mathrm{N}_{3}$ (11)}

To a $10 \mathrm{~mL}$ flask were added CNTs (50 mg), 10 (122.96 mg, $0.91 \mathrm{mmol})$, dry DMF $(5.2 \mathrm{~mL})$ and the mixture was sonicated 
in an ultrasound bath $(10 \mathrm{~min})$. To the dispersion was added isopentyl nitrite $97.62 \mathrm{mg}(0.83 \mathrm{mmol})$ was added and the mixture was stirred at $60{ }^{\circ} \mathrm{C}$ for $24 \mathrm{~h}$. The suspension was filtered over a $0.2 \mu \mathrm{m}$ PTFE membrane, and the solid was washed with DMF and acetone until colorless solution obtained. CNTsAzide were recovered with acetone and dried to afford $50.5 \mathrm{mg}$ of a black powder. FTIR (KBr): $2118 \mathrm{~nm} \mathrm{~N}$ stretching. Elemental analysis C, 66.94\%; H, 3.83\%; N, 7.00\%. Azide loading based on elemental analysis $1.63 \mathrm{mmol} / \mathrm{g}$.

\section{Synthesis of GPs- $\mathrm{N}_{3}(\mathbf{1 2})$}

To a $25 \mathrm{~mL}$ flask were added GPs $(33 \mathrm{mg}), \mathbf{1 0}(82 \mathrm{mg}$ $0.61 \mathrm{mmol}), 1,2$-dichlorobenzene $(2.64 \mathrm{~mL})$ and dry DMF $(5.2 \mathrm{~mL})$. The mixture was dispersed in an ultrasound bath. Then, isopentyl nitrite $(63.9 \mathrm{mg}, 0.54 \mathrm{mmol})$ was added and the mixture was stirred at $60{ }^{\circ} \mathrm{C}$ for $24 \mathrm{~h}$. The suspension was filtered over a $0.2 \mu \mathrm{m}$ ptfe membrane. Thereafter, the solid was thoroughly washed with DMF and acetone until a colorless solution was obtained. The material was recovered with acetone and dried to obtain $32.5 \mathrm{mg}$ of a black powder. FTIR (KBr) $2119 \mathrm{~nm} \mathrm{~N}$ stretching. Elemental analysis C, 97.7\%; H, $0.15 \%$; N, $0.31 \%$. Azide loading based on elemental analysis $0.075 \mathrm{mmol} / \mathrm{g}$.

\section{Synthesis of CNTs-Click-PO (13)}

To a $25 \mathrm{~mL}$ flask were added 11 (30 mg, $0.049 \mathrm{mmol}$ of azide), phosphine oxide 3 (17.75 mg, $0.059 \mathrm{mmol}, 1.2$ equiv) of copper iodide triethyl phosphite ( $3.49 \mathrm{mg}, 0.0098 \mathrm{mmol}, 0.2$ equiv) and $8.5 \mathrm{~mL}$ of degassed dry DMF. The mixture dispersed in an ultrasound bath under inert atmosphere. After dispersion, DIPEA $18.35 \mathrm{mg}$ ( $0.142 \mathrm{mmol}, 2.9$ equiv) was added and the mixture was stirred at $60{ }^{\circ} \mathrm{C}$ for $48 \mathrm{~h}$. The suspension was filtered over a $0.2 \mu \mathrm{m}$ PTFE membrane and the solid was thoroughly washed with DMF and acetone until a colorless solution was obtained. The material was recovered and dried to afford $28.2 \mathrm{mg}$ of a black powder. FTIR (KBr) 3105, 2103, 1722, $1658,1579,1386,1170$ and $1118 \mathrm{~cm}^{-1}$. ICP AES analysis: phosphorus $0.847 \%$.

\section{Synthesis of GPs-Click-PO (14)}

To a $25 \mathrm{~mL}$ flask were added with $12(28.5 \mathrm{mg}, 0.0023 \mathrm{mmol}$ of azide), phosphine oxide 3 ( $1 \mathrm{mg}, 0.0027 \mathrm{mmol}, 1.2$ equiv) copper iodide triethyl phosphite $(0.162 \mathrm{mg}, 0.00045 \mathrm{mmol}$, 0.2 equiv) and degassed 1,2-dichlorobenzene $(8.5 \mathrm{~mL})$. The mixture was dispersed in an ultrasound bath. DIPEA $(1 \mathrm{mg}$, $0.0078 \mathrm{mmol}, 2.9$ equiv) was added and the reaction mixture was stirred at $60{ }^{\circ} \mathrm{C}$ for $48 \mathrm{~h}$. The suspension was diluted with acetone and centrifuged (10 $\mathrm{min}$ at $1500 \mathrm{rcf}$ ) to remove $1,2-$ dichlorobenzene. Then the solid was dispersed in DMF and filtered over a $0.2 \mu \mathrm{m}$ PTFE membrane. The solid was washed with DMF and acetone until colorless solution obtained. The material was recovered and characterized to afford $28.7 \mathrm{mg}$ of a black powder. ICP AES analysis: phosphorus $0.057 \%$.

\section{General procedure for the reduction of PO}

To a Pyrex tube was added to carbonaceous substrate $(5 \mathrm{mg})$, degassed 1,2-dichlorobenzene $(1 \mathrm{~mL})$ and the mixture was dispersed in an ultrasound bath. The mixture was then added with triethyl phosphite $(387.6 \mathrm{mg}, 2.33 \mathrm{mmol})$ and trichlorosilane (134.2 $\mathrm{mg}, 0.99 \mathrm{mmol})$ and the reaction left $48 \mathrm{~h}$ at $100{ }^{\circ} \mathrm{C}$ under vigorous stirring. The material was washed by repeated dispersion and centrifugation cycles (10 min at $1400 \mathrm{rcf}$ ) one cycle with isopropanol to remove the reaction solvent, three cycles with $1 \mathrm{M}$ aqueous sodium hydroxide, three cycles with aqueous hydrogen chloride $0.1 \mathrm{M}$, three cycles with methanol and three cycles with isopropyl ether. The reduction was checked by XPS spectroscopy.

\section{General procedure for the Staudinger ligation}

To a pirex tube were added with phosphine decorated CNTs (8-red, $5 \mathrm{mg}$ ) degassed dry toluene $(1 \mathrm{~mL})$, carboxylic acid $(0.19 \mathrm{mmol}, 1$ equiv), a solution of benzyl azide $(0.19 \mathrm{mmol})$ in $0.5 \mathrm{~mL}$ of degassed toluene and phenylsilane $(21 \mathrm{mg}$, $0.19 \mathrm{mmol}, 1$ equiv) and the reaction was stirred at $110{ }^{\circ} \mathrm{C}$ under nitrogen atmosphere for $22 \mathrm{~h}$. The catalyst was recovered by centrifugation $(2 \times 15 \mathrm{~min}$ at $1500 \mathrm{rcf})$ and dispersion with toluene $20 \mathrm{~mL}$. The solution was evaporated under vacuum giving the crude product, the amide was recovered after flash chromatography (silica) using a mixture of hexane/ethyl acetate $1: 1$.

$N$-Benzylbenzamide (17): $R_{\mathrm{f}}=0.48$ (hexane/ethyl acetate 1:1), yield $75 \%$. Spectral data already reported in literature [24].

$N$-Phenylcinnamamide (19): $R_{\mathrm{f}}=0.77$ (hexane/ethyl acetate $1: 1$ ), yield $55 \%$. Spectral data already reported in literature [24].

$N$-Phenylcinnamamide (21): $R_{\mathrm{f}}=0.64$ (hexane/ethyl acetate $1: 1$ ), yield $58 \%$. Spectral data already reported in literature [24].

\section{Supporting Information}

\section{Supporting Information File 1}

IR, Raman and XPS spectra, NMR spectra of amides 17, 19 and $\mathbf{2 1}, \mathrm{GC}$ analysis of $\mathbf{1 7}$ and $\mathbf{2 1}$.

[http://www.beilstein-journals.org/bjnano/content/ supplementary/2190-4286-8-52-S1.pdf]

\section{Acknowledgements}

SC acknowledges Ente Cassa di Risparmio di Firenze for financial contribution. 


\section{References}

1. lijima, S. Nature 1991, 354, 56. doi:10.1038/354056a0

2. Kroto, H. W.; Heath, J. R.; O'Brien, S. C.; Curl, R. F.; Smalley, R. E. Nature 1985, 318, 162. doi:10.1038/318162a0

3. Novoselov, K. S.; Geim, A. K.; Morozov, S. V.; Jiang, D.; Zhang, Y.; Dubonos, S. V.; Grigorieva, I. V.; Firsov, A. A. Science 2004, 306, 666 doi:10.1126/science.1102896

4. Saeed, K.; Park, S.-Y.; Lee, H.-J.; Baek, J.-B.; Huh, W.-S. Polymer 2006, 47, 8019. doi:10.1016/j.polymer.2006.09.012

5. Tasis, D.; Tagmatarchis, N.; Bianco, A.; Prato, M. Chem. Rev. 2006, 106, 1105. doi:10.1021/cr050569o

6. Dirian, K.; Herranz, M. Á.; Katsukis, G.; Malig, J.; Rodríguez-Pérez, L.; Romero-Nieto, C.; Strauss, V.; Martín, N.; Guldi, D. M. Chem. Sci. 2013, 4, 4335. doi:10.1039/c3sc51100f

7. Wong, B. S.; Yoong, S. L.; Jagusiak, A.; Panczyk, T.; Ho, H. K.; Ang, W. H.; Pastorin, G. Adv. Drug Delivery Rev. 2013, 65, 1964 doi:10.1016/j.addr.2013.08.005

8. Campidelli, S.; Ballesteros, B.; Filoramo, A.; Díaz, D. D.; de la Torre, G.; Torres, T.; Rahman, G. M. A.; Ehli, C.; Kiessling, D.; Werner, F.; Sgobba, V.; Guldi, D. M.; Cioffi, C.; Prato, M.; Bourgoin, J.-P. J. Am. Chem. Soc. 2008, 130, 11503. doi:10.1021/ja8033262

9. Schmidt, G.; Gallon, S.; Esnouf, S.; Bourgoin, J.-P.; Chenevier, P. Chem. - Eur. J. 2009, 15, 2101. doi:10.1002/chem.200801801

10. Strom, T. A.; Dillon, E. P.; Hamilton, C. E.; Barron, A. R. Chem. Commun. 2010, 46, 4097. doi:10.1039/c001488e

11. Lutz, J.-F. Angew. Chem., Int. Ed. 2007, 46, 1018. doi:10.1002/anie.200604050

12. Fedeli, S.; Brandi, A.; Venturini, L.; Chiarugi, P.; Giannoni, E.; Paoli, P.; Corti, D.; Giambastiani, G.; Tuci, G.; Cicchi, S. J. Mater. Chem. B 2016 , 4, 3823. doi:10.1039/C6TB00304D

13. Tuci, G.; Luconi, L.; Rossin, A.; Baldini, F.; Cicchi, S.; Tombelli, S.; Trono, C.; Giannetti, A.; Manet, I.; Fedeli, S.; Brandi, A.; Giambastiani, G. ChemPlusChem 2015, 80, 704. doi:10.1002/cplu.201402391

14. Choi, W.; Lahiri, I.; Seelaboyina, R.; Kang, Y. S. Crit. Rev. Solid State Mater. Sci. 2010, 35, 52. doi:10.1080/10408430903505036

15. Muleja, A. A.; Mbianda, X. Y.; Krause, R. W.; Pillay, K. Carbon 2012, 50, 2741. doi:10.1016/j.carbon.2012.02.033

16. Hamilton, C. E.; Ogrin, D.; McJilton, L.; Moore, V. C.; Anderson, R.; Smalley, R. E.; Barron, A. R. Dalton Trans. 2008, 22, 2937. doi:10.1039/b801166d

17. Fareghi-Alamdari, R.; Haqiqi, M. G.; Zekri, N. New J. Chem. 2016, 40, 1287. doi:10.1039/C5NJ02227D

18. Methot, J. L.; Roush, W. R. Adv. Synth. Catal. 2004, 346, 1035. doi:10.1002/adsc.200404087

19. Xu, S.; He, Z. RSC Adv. 2013, 3, 16885. doi:10.1039/c3ra42088d

20. Xiao, Y.; Sun, Z.; Guo, H.; Kwon, O. Beilstein J. Org. Chem. 2014, 10, 2089. doi:10.3762/bjoc. 10.218

21. Denton, R. M.; An, J.; Adeniran, B. Chem. Commun. 2010, 46, 3025. doi:10.1039/c002825h

22. Denton, R. M.; Tang, X.; Przeslak, A. Org. Lett. 2010, 12, 4678. doi:10.1021/ol102010h

23. Buonomo, J. A.; Aldrich, C. C. Angew. Chem., Int. Ed. 2015, 54, 13041. doi:10.1002/anie.201506263

24. Kosal, A. D.; Wilson, E. E.; Ashfeld, B. L. Angew. Chem., Int. Ed. 2012, 51, 12036. doi:10.1002/anie.201206533

25. Tang, X.; An, J.; Denton, R. M. Tetrahedron Lett. 2014, 55, 799. doi:10.1016/j.tetlet.2013.11.098
26. Wu, B.; Kuang, Y.; Zhang, X.; Chen, J. Nano Today 2011, 6, 75. doi:10.1016/j.nantod.2010.12.008

27. Esumi, K.; Ishigami, M.; Nakajima, A.; Sawada, K.; Honda, H. Carbon 1996, 34, 279. doi:10.1016/0008-6223(96)83349-5

28. Shaffer, M. S. P.; Fan, X.; Windle, A. H. Carbon 1998, 36, 1603. doi:10.1016/S0008-6223(98)00130-4

29. lannazzo, D.; Mazzaglia, A.; Scala, A.; Pistone, A.; Galvagno, S.; Lanza, M.; Riccucci, C.; Ingo, G. M.; Colao, I.; Sciortino, M. T.; Valle, F.; Piperno, A.; Grassi, G. Colloids Surf., B 2014, 123, 264. doi:10.1016/j.colsurfb.2014.09.025

30. Castelaín, M.; Martínez, G.; Merino, P.; Martín-Gago, J. Á.; Segura, J. L.; Ellis, G.; Salavagione, H. J. Chem. - Eur. J. 2012, 18, 4965. doi:10.1002/chem.201102008

31. Kumar, I.; Rana, S.; Cho, J. W. Chem. - Eur. J. 2011, 17, 11092. doi:10.1002/chem.201101260

32. Georgakilas, V.; Otyepka, M.; Bourlinos, A. B.; Chandra, V.; Kim, N.; Kemp, K. C.; Hobza, P.; Zboril, R.; Kim, K. S. Chem. Rev. 2012, 112, 6156. doi:10.1021/cr3000412

33. Fedeli, S.; Paoli, P.; Brandi, A.; Venturini, L.; Giambastiani, G.; Tuci, G.; Cicchi, S. Chem. - Eur. J. 2015, 21, 15349. doi:10.1002/chem.201501817

34. Sharma, R.; Baik, J. H.; Perera, C. J.; Strano, M. S. Nano Lett. 2010, 10, 398. doi:10.1021/n1902741x

35. Scheibe, B.; Borowiak-Palen, E.; Kalenczuk, R. J. Mater. Charact. 2010, 61, 185. doi:10.1016/j.matchar.2009.11.008

36. Wu, H.-C.; Yu, J.-Q.; Spencer, J. B. Org. Lett. 2004, 6, 4675 doi:10.1021/ol048227c

37. Swartz, W. E., Jr.; Ruff, J. K.; Hercules, D. M. J. Am. Chem. Soc. 1972 , 94, 5227. doi:10.1021/ja00770a015

38. Zhang, X.; Liu, H.; Hu, X.; Tang, G.; Zhu, J.; Zhao, Y. Org. Lett. 2011, 13, 3478. doi:10.1021/ol201141m

39. Ha-Thi, M.-H.; Souchon, V.; Hamdi, A.; Métivier, R.; Alain, V.; Nakatani, K.; Lacroix, P. G.; Genêt, J.-P.; Michelet, V.; Leray, I. Chem. - Eur. J. 2006, 12, 9056. doi:10.1002/chem.200600464

40. Andersen, J.; Madsen, U.; Björkling, F.; Liang, X. Synlett 2005, 2209. doi:10.1055/s-2005-872248

\section{License and Terms}

This is an Open Access article under the terms of the Creative Commons Attribution License (http://creativecommons.org/licenses/by/4.0), which permits unrestricted use, distribution, and reproduction in any medium, provided the original work is properly cited.

The license is subject to the Beilstein Journal of Nanotechnology terms and conditions: (http://www.beilstein-journals.org/bjnano)

The definitive version of this article is the electronic one which can be found at: $\underline{\text { doi:10.3762/bjnano.8.52 }}$ 